\title{
Is Science Learning Magic?
}

Reviewed by: Stuart Marcovitch, Robert E. Guttentag

Marcovitch, S. \& Guttentag, R. E. (2012). Is science learning magic? [Review of book The journey from child to scientist: Integrating cognitive development and the education sciences, by S. Carver and J. Shrager (Eds.)]. PsycCRITIQUES, 57(44).

This article may not exactly replicate the final version published in the APA journal.

Made available courtesy of American Psychological Association (APA): http://www.apa.org/pubs/journals/cnt/index.aspx

***(C) American Psychological Association. Reprinted with permission. No further reproduction is authorized without written permission from the APA. This version of the document is not the version of record. Figures and/or pictures may be missing from this format of the document. ***

\section{Abstract:}

A review of the book "The Journey From Child to Scientist: Integrating Cognitive Development and the Education Sciences" by Sharon M. Carver and Jeff Shrager.

Keywords: Book review | Science | Education | Beliefs | Supernatural | Magical Thinking

\section{Article:}

The Journey From Child to Scientist: Integrating Cognitive Development and the Education Sciences by Sharon M. Carver and Jeff Shrager (Eds.) Washington, DC: American Psychological Association, 2012. 305 pp. ISBN 978-1-4338-1138-8. \$79.95

In its June 5, 2002, issue, the satirical newspaper The Onion trumpeted the news that "the National Science Foundation's annual symposium concluded Monday, with the 1,500 scientists in attendance reaching the consensus that science is hard" ("National Science Foundation: Science Hard,” 2002, para. 1). Part of the humor, of course, derives from the fact that, for American students, and for Americans more generally, it does seem that science is very hard.

Thus, for example, the results from the Third International Mathematics and Science Study indicated that American high school 12th-grade students scored above only students from Cyprus and South Africa out of 21 countries included in the study, and the science knowledge results for U.S. 15-year-olds on the recent Program for International Student Assessment were almost as dismal. In terms of science-based beliefs, a Gallup poll taken on the event of Darwin's 200th birthday in 2009 revealed that only 39 percent of Americans profess to believe in the theory of evolution, whereas the hugely successful book and DVD The Secret has convinced many that the content of our thoughts can cause external events to be rearranged so that our desires can be met. Clearly, something has not gone well in the learning of science by American students. 
The science of science learning is a field of remarkably recent provenance. The Journey From Child to Scientist: Integrating Cognitive Development and the Education Sciences, a 13-chapter edited volume, is based upon presentations at the 37th Carnegie Symposium on Cognition, which in 2009 was organized to commemorate the pioneering and highly influential achievements and contributions of David Klahr.

One of Klahr's major contributions was to trumpet the control of variables strategy (CVS) as a hallmark of science learning (Klahr, 2000). As the name implies, CVS involves holding all extraneous variables constant when one is analyzing the effects of a single variable; application of the strategy is of fundamental importance for science because failure to do so introduces confounds into a study that render precise interpretations of the study's findings impossible.

One general thread running through the diverse chapters is the championing of the value of applied research in cognitive development. A number of the chapters highlight the bidirectional benefits of such an approach such that basic research in cognitive development may serve to inform educational practice, while at the same time, research on the effects of different kinds of pedagogies may inform and challenge foundational theories of children's thinking.

Klahr's own work comparing guided discovery learning with a form of direct instruction is a case in point: Klahr found that children in the direct instruction condition were not only more likely to learn the basics of CVS (many children in the discovery learning condition never "discovered" the strategy at all), they were also just as likely to apply the strategy to near and far transfer tasks, as were those children in the discovery learning condition who discovered the CVS strategy.

A second general theme of many of the volume's chapters is that science learning should involve not just the acquisition of scientific knowledge but also the learning of the fundamentals of the scientific method. Indeed, in many of the chapters, the importance of children learning not just the what of science but also the how is taken as a given, and much of the research on children's science learning discussed in this volume focuses on their learning of different aspects of the way that science is done. Thus, besides Klahr's own work on CVS, other contributors focus more on the social and collaborative elements of the way that science is typically really done, arguing that it is important for children to experience and appreciate those aspects of real-world scientific inquiry.

The focus on children's learning of the how of science raises the tension (for the most part not directly addressed in this volume) that exists between, on the one hand, the evidence that "science is hard" and the low rates of belief in some scientific concepts (e.g., evolution), and, on the other hand, the oft-used and complementary metaphors of the "child as scientist" and "scientist as child"-metaphors that are explicitly referenced by the editors of the present volume. In particular, if the parallels are so strong between the nature of scientific inquiry and the natural learning processes of the child, why does the embracing of knowledge based upon the application of the principles of the scientific method seem so foreign to so many people? 
Is it simply the case that instruction in other modes of belief formation (grounded, as those other methods often are, in fundamental value systems of cultural and religious groups) is pedagogically more sound than are the methods used to instruct children in the learning of scientific methods? Or, might it be the case that even the most basic of elements of scientific thinking do not come as naturally to people as the metaphor of child as scientist might imply? Answers to these questions can be found in recent research on the naturalness of magical and religious thinking - forms of thinking that are antithetical to the forms of thinking that support scientific inquiry. Thus, for example, Barrett (Barrett, Richert, \& Driesenga, 2001; Knight, Sousa, Barrett, \& Atran, 2004) has discussed the ways in which belief in an all-knowing supernatural deity builds upon preschool-aged children's early nonrepresentational theory of mind, whereas Kelemen (2004) has argued that children are naturally prone to teleological thinking about natural organisms, events, and structures - a form of thinking that she refers to as the design stance and that fits well with religion-based rather than science-based explanations for natural phenomena (including the origin of species).

In addition, Rozin and others (e.g., Birch \& Bloom, 2007; Langer, 1975; Pronin, Wegner, McCarthy, \& Rodriguez, 2006) have noted that in some cases, even well-educated adults make judgments consistent with magical modes of thinking about causality, even while verbally denying supernatural or magical causal effects. Nemeroff and Rozin (1989), for example, found that University of Pennsylvania students judged that members of a fictional tribe were more likely to be irritable and loud if the tribe members were described as eating wild boars than if the tribe members were described as eating sea turtles-judgments consistent with a magical belief that "we are what we eat."

These and other related demonstrations of magical thinking by adults suggest, at a minimum, that science learning may be "hard" not only because of the demands it sometimes places on our ability to understand abstract concepts and to engage in mental simulation (Geary, Chapter 4) and to construct, revise, apply, and defend models of the natural world (Lehrer \& Schauble, Chapter 9), but also because scientific explanations for natural phenomena must compete with explanations that are not only firmly embedded in strongly held value systems but which also are compatible with and build seamlessly upon early-developing intuitions and modes of thought. Thus, it is not that the scientist is immune from magical thinking, but rather he or she is trained to inhibit it when necessary. But how does the child develop scientific thought?

The evidence for the "naturalness" of magical or supernatural thinking does not preclude the possibility that the basic building blocks for scientific thinking may also be present (albeit in an implicit form) from very early in life, and, indeed, one proposal regarding the development of scientific thinking is that a major transition from child to scientist is the onset of an explicit understanding of the scientific principles that children already possess and apply implicitly. The inspiration of this hypothesis comes initially from the works of Piaget (e.g., Piaget \& Cook, 1952), and more critically from Karmiloff-Smith’s (1992) representational redescription theory that states that children initially master activities implicitly, and it is only with introspection that the implicit process can become explicit. In turn, explicit processes can be analyzed, manipulated, deconstructed, and reconstructed to accommodate internal and external demands. 
For the purpose of the present argument, children are armed with the tools of scientific thought: curiosity (Smock \& Holt, 1962), the ability to detect patterns in the environment (Saffran, Aslin, \& Newport, 1996), persistence (Lufi \& Cohen, 1987), and rudimentary hypothesis-testing skills (Gopnik, Meltzoff, \& Kuhl, 1999). Unfortunately, they are unaware that they possess these tools, unaware that they are using them, and unable to devote time and effort strategically to refine them.

By discovering that they already possess critical reasoning skills and by learning the appropriate associated vocabulary, children are then able to reflect upon their usage of these skills and begin to modify them accordingly. With appropriate and timely instruction and mentorship, motivated children can build upon their newly realized scientific abilities and head toward sophisticated scientific thought.

This perspective encourages a subtle, but important, distinction on how best to develop scientific thinking in our children. Rather than teach children "new" concepts regarding scientific thought, it would be better advised to work with the children in helping them discover, label, and modify their existing scientific knowledge. For example, hypothesis testing is not a concept to be taught, memorized, and applied. Rather, children should be placed in contexts where they can repeatedly use their implicit hypothesis-testing skills; as the situations get more challenging, they should be afforded the opportunity to reflect upon their processes and, in doing so, allow for self-guided modifications.

The role of the instructor would be to facilitate the process by gently guiding the students, pointing out logical inconsistencies and confounds, ensuring that appropriate vocabulary is being used, and providing encouraging, motivating contexts (see Piaget, 1972, for similar ideas). Note that we are not advocating that this is an end point to developing an affinity toward science, but instead we see it as a necessary first step-one that currently many students do not take on their journey to magical thinking.

We realize that this is contrary to Klahr and others' findings that CVS must be taught explicitly, as it is not likely to be discovered spontaneously (Chen \& Klahr, 1999). Although it may appear paradoxical, we see this line of reasoning as support for our argument. Of course it is very challenging for children to make explicit their understanding of CVS, most likely because they do not have sufficient opportunity to master, and thus make explicit, these skills in everyday life. Our point is that teachers are invaluable to this process, and when children are taught how to think scientifically, it should be in the context of hands-on experience in which children are urged to reason through the process.

In fact, in our view it would be very effective to learn about CVS in the context of learning about human behavior. Behavioral science lends itself well to dealing with multiple predictor variables, and, as many instructors of university-level psychology classes can attest to, has a natural tendency to want to address confounds and issues of generalizability.

Given school-aged children's advances in understanding the causes of human behavior-by five years of age, they have a complex understanding that behavior is caused by internal states that differ from person to person (Wellman, Cross, \& Watson, 2001) - it is conceivable that there would be a focused interest on learning about the multiple causes of human behavior and how we 
can determine experimentally the individual roles of each one. We are not suggesting, of course, that we teach research methods to elementary school children, but we do believe that carefully selected phenomena found in our psychology textbooks can be introduced and effectively used.

This would leave us with an uncanny circumstance that many of our colleagues have already noted, namely, that the teaching of STEM (science, technology, engineering, and math) in our schools is going to have to rely on the tools of behavioral science, even though STEM itself does not encapsulate the behavioral sciences. Perhaps this recognition might be a way to initiate the path that would eventually lead to increased enthusiasm for and abilities to perform the STEM disciplines.

\section{References}

Barrett, J. L., Richert, R., \& Driesenga, A. (2001). God’s beliefs versus mother's: The development of non-human agent concepts. Child Development, 72, 50-65. doi:10.1111/14678624.00265

Birch, S. A., \& Bloom, P. (2007). The curse of knowledge in reasoning about false beliefs. Psychological Science, 18(5), 382-386. doi:10.1111/j.1467-9280.2007.01909.x

Chen, Z., \& Klahr, D. (1999). All other things being equal: Acquisition and transfer of the control of variables strategy. Child Development, 70, 1098-1120. doi:10.1111/1467-8624.00081

Gopnik, A., Meltzoff, A. N., \& Kuhl, P. K. (1999). The scientist in the crib: Minds, brains, and how children learn. New York, NY: Morrow.

Karmiloff-Smith, A. (1992). Beyond modularity: A developmental perspective on cognitive science. Cambridge, MA: MIT Press.

Kelemen, D. (2004). Are children “intuitive theists”? Reasoning about purpose and design in nature. Psychological Science, 15, 295-301. doi:10.1111/j.0956-7976.2004.00672.x

Klahr, D. (2000). Exploring science: The cognition and development of discovery processes. Cambridge, MA: MIT Press.

Knight, N., Sousa, P., Barrett, J., \& Atran, S. (2004). Children’s attributions of beliefs to humans and God: Cross-cultural evidence. Cognitive Science, 28, 117-126.

doi:10.1207/s15516709cog2801_6

Langer, E. J. (1975). The illusion of control. Journal of Personality and Social Psychology, 32, 311-328. doi:10.1037/0022-3514.32.2.311

Lufi, D., \& Cohen, A. (1987). A scale for measuring persistence in children. Journal of Personality Assessment, 51, 178-185. doi:10.1207/s15327752jpa5102_2

National Science Foundation: Science hard. (2002, June 5). The Onion. Retrieved from 
http://www.theonion.com/articles/national-science-foundation-science-hard,1405/

Nemeroff, C., \& Rozin, P. (1989). "You are what you eat”: Applying the demand-free “impressions” technique to an unacknowledged belief. Ethos, 17, 50-69.

doi:10.1525/eth.1989.17.1.02a00030

Piaget, J. (1972). Intellectual evolution from adolescence to adulthood. Human Development, 15, 1-12. doi:10.1159/000271225

Piaget, J., \& Cook, M. (1952). The origins of intelligence in children. New York, NY: Norton. doi:10.1037/11494-000

Pronin, E., Wegner, D. M., McCarthy, K., \& Rodriguez, S. (2006). Everyday magical powers: The role of apparent mental causation in the overestimation of personal influence. Journal of Personality and Social Psychology, 91, 218-231. doi:10.1037/0022-3514.91.2.218

Saffran, J. R., Aslin, R. N., \& Newport, E. L. (1996, December 13). Statistical learning by 8month-old infants. Science, 274(5294), 1926-1928. doi:10.1126/science.274.5294.1926

Smock, C. D., \& Holt, B. (1962). Children's reactions to novelty: An experimental study of “curiosity motivation.” Child Development, 33, 631-642. doi:10.2307/1126663

Wellman, H. M., Cross, D., \& Watson, J. (2001). Meta-analysis of theory-of-mind development: The truth about false belief. Child Development, 72, 655-684. doi:10.1111/1467-8624.00304 